\title{
Coulisses
}

Revue de théâtre

1 | Printemps 1990

Varia

\section{Le théâtre universitaire de Franche-Comté}

Rédaction

\section{OpenEdition}

\section{Journals}

Édition électronique

URL : http://journals.openedition.org/coulisses/1554

DOI : $10.4000 /$ coulisses. 1554

ISSN : 2546-9460

\section{Éditeur}

Presses universitaires de Franche-Comté

\section{Édition imprimée}

Date de publication : 1 avril 1990

Pagination : $39-40$

ISSN : 1150-594X

\section{Référence électronique}

Rédaction, «Le théâtre universitaire de Franche-Comté », Coulisses [En ligne], 1 | Printemps 1990, mis en ligne le 04 juillet 2017, consulté le 22 octobre 2019. URL : http://journals.openedition.org/coulisses/ 1554 ; DOI : 10.4000/coulisses. 1554

Ce document a été généré automatiquement le 22 octobre 2019

Coulisses 


\title{
Le théâtre universitaire de Franche- Comté
}

\author{
Rédaction
}

1 Créé en octobre 1986, le T.U.F.C. renoue avec une tradition. Association loi 1901, « il se donne pour but une rencontre entre tous les usagers de l'Université de Franche-Comté, étudiants, salariés, auditeurs de l'Université Ouverte, autour de la pratique théâtrale, de manière à créer un pôle d'attraction culturelle au sein de l'Université comme à l'extérieur. " (article I des statuts). La formation théâtrale et la mise en scène sont assurés par un comédien-animateur professionnel, Joseph Melcore, l'administration et la programmation par Lucile Garbagnati. Si le T.U.F.C. participe à l'enseignement en assurant une partie de la formation pratique dans les modules d'enseignement portant sur le théâtre, son activité essentielle n'a rien à voir avec les examens.

2 Il propose à ses membres différentes activités: initiation à la pratique théâtrale, production et diffusion de pièces, stages avec des professionnels, conférences, organisation des manifestations, publication, de manière à ce que soient perçus les différents enjeux de toute représentation. Il s'efforce avec le concours de l'Université Ouverte de développer l'art d'être un spectateur par un cycle de conférences Littérature et représentation sur les spectacles programmés à Beasnçon et en s'aventurant dans la publication de cette revue Coulisses.

3 Depuis sa fondation le T.U.F.C. a créé : Le Laboratoire, création collective sur Pasteur et la recherche scientifique, Essence sur l'automobile, Actes, montage sur l'amour (juin 1987) ; Trajectoires (juin 1988) et Voix (juin 1989) sur la Révolution qui ont obtenu le label de la Mission du Bicentenaire, Mystère bouffe de Dario Fo (juin 1989\}, La mirifique histoire de Blanc Bec ou l'histoire de la formation continue (décembre 1989).

4 Il a organisé un colloque en 1988 Théâtre et révolution, également « labellisé » et en a publié les Actes. 


\section{Programme d'activité}

\section{Pratique théâtrale}

5 Expression : approche des techniques du comédien sans but de représentation : $1^{\text {er }}$ trimestre.

6 Production : Electre 90, juin 1990 sur le campus de la Bouloie dans le cadre de Besançon Ville Ouverte aux Jeunes.

7 Diffusion : Reprise de Mystère Bouffe de Dario Fo à Pontarlier, Besançon, Uège, Québec.

8 Stages avec des professionnels.

9 Relations avec l'entreprise: Stage à la demande des entreprises. Création de spectacles sur l'entreprise : Histoire de la formation continue, commande de I'I.U.F.C., déc. 1989.

10 Relations internationales : Participation aux Rencontres Internationales de Théâtre Universitaire de Liège: mars 1990. Programme d'échanges avec le Théâtre du Funambule de Hull (Outaouais, Québec) dans le cadre du programme Production de l'office franco-québecois pour la jeunesse.

\section{Diffusion de la culture théâtrale}

11 Cycle Littérature et représentation dans le cadre de l'Université Ouverte.

\section{Publications}

Revue bisannuelle : Coulisses.

Actes du colloque Théâtre et Révolution, collection du Bicentenaire de la Révolution

française, Annales littéraires de l’Université de Besançon.

\section{Rencontres internationales}

Théâtre et université - 17-21 avril 1989. 


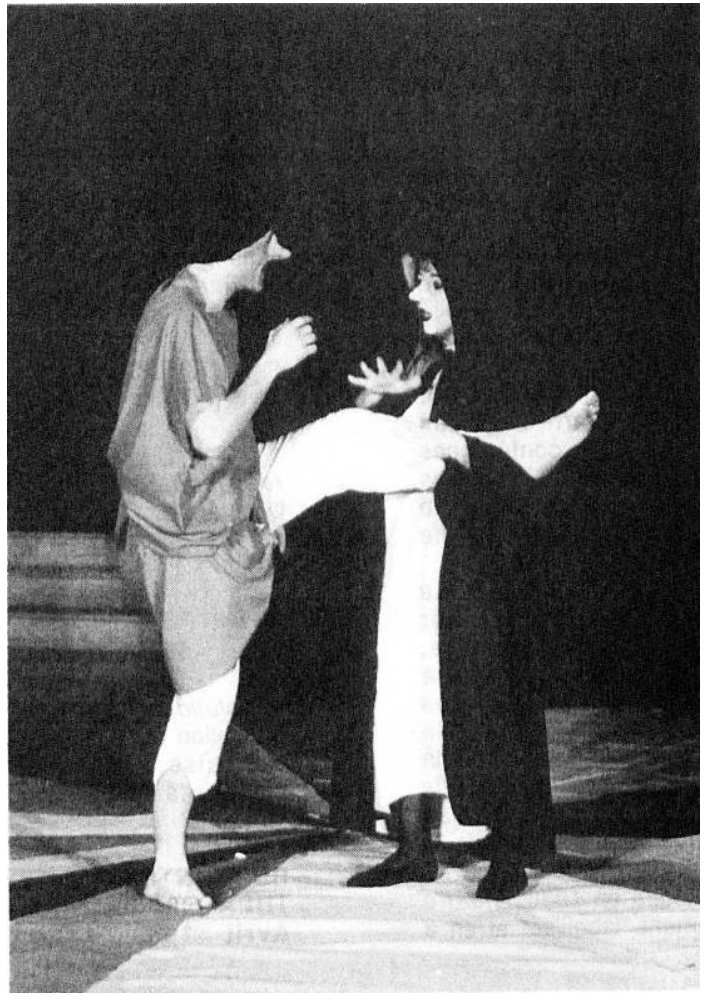

(C) VALÉRIE GOY.

16 L'adhésion au T.U.F.C. s'élève à 100 francs. Elle donne droit au tarif de groupe à l'Espace Planoise, au C.N.D. (Théâtre du Casino), à assister à la Générale de l'opéra présenté dans le cycle Littérature et représentation.

17 Contact : Faculté des Lettres, 30, rue Mégevand, 25030 - Besançon Cedex. 